\title{
New Vision, Mission, and Values of the Japanese Circulation Society
}

\author{
Mari Ishida, MD, PhD; Chisa Matsumoto, MD, PhD; Keisuke Kida, MD, PhD; \\ Memori Fukuda, MD; Nobuyuki Kagiyama, MD, PhD; Kenya Kusunose, MD, PhD; \\ Shingo Matsumoto, MD, PhD; Seitaro Nomura, MD, PhD; Takahiro Okumura, MD, PhD; \\ Yasutsugu Shiono, MD, PhD; Tatsunori Taniguchi, MD, PhD; Atsushi Mizuno, MD, PhD; \\ Takuya Kishi, MD, PhD; Koichi Node, MD, PhD; Issei Komuro, MD, PhD; \\ Ken-ichi Hirata, MD, PhD; Directors of the Japanese Circulation Society
}

$\mathbf{T}$ he Japanese Circulation Society (JCS) was inaugurated in 1935 by Dr. Toshikazu Mashimo at the former Kyoto Imperial University (now Kyoto University) with the publication of a bulletin describing circulation studies. On the first page of the first issue of the official journal, later known as the Japanese Circulation Journal, the founder's enthusiasm was expressed through a statement entitled "Our Mission". The mission of the Society was not only to publish scientific papers or hold scientific meetings, but also to encourage and support young physicians, promote research on cardiovascular disease (CVD), and work towards its prevention. In addition, the mission emphasized the importance of passing on new knowledge in cardiology to general physicians. The statement concluded by saying that the accomplishment of the mission would not only benefit members of the JCS, but also bring happiness to society as a whole. This mission, full of the passion of the founders, has been passed on over the decades and the JCS has accomplished much in its continual efforts to promote science and medicine, develop human resources, and improve public health over the past 86 years.

Over this time, the JCS itself and the circumstances of the Society have dramatically changed and the number of members has increased dramatically. When the JCS was established, the Society consisted of 299 cardiologists and almost the same number of cardiologists participated in the first JCS general meeting held in 1936. Considering the transportation situation at that time, this number shows how eager physicians were to attend the first meeting. As of 2020, the number of JCS members, including associate members, had reached 30,000 and members consist of not only cardiologists but also other cardiovascular specialists including nurses, therapists, dietitians, technicians, educators, and scientists. In addition, many international honorary members support the activities of the JCS. From a societal perspective, as the JCS has grown, innumerable and significant social changes have occurred, such as the development of science and technology, changes in the types and prevalence of diseases, aging of society, a growing demand for cardiovascular care, increased availability of information, globalization, disparity issues, and diversification of values in the general population.

As a professional group of CVD experts, we have repeatedly pondered what the Society could do for the enhancement of cardiovascular health by adapting to the changes in the world. In this context, the Society has recognized the necessity of revising its mission and clearly

J-STAGE Advance Publication released online October 22, 2021

Department of Cardiovascular Physiology and Medicine, Graduate School of Biomedical and Health Sciences, Hiroshima University, Hiroshima (M.I.); New Mission Working Group, The Japanese Circulation Society, Tokyo (M.I., C.M., K. Kida, M.F., N.K., K. Kusunose, S.M., S.N., T.O., Y.S., T.T., K.N.); Department of Cardiology, Tokyo Medical University, Tokyo (C.M.); Department of Pharmacology, St. Marianna University School of Medicine, Kawasaki (K. Kida); Department of Cardiology, School of Medicine, Keio University, Tokyo (M.F.); Department of Cardiovascular Biology and Medicine, Juntendo University, Tokyo (N.K.); Department of Cardiovascular Medicine, Tokushima University Hospital, Tokushima (K. Kusunose); Department of Cardiovascular Medicine, Department of Internal Medicine, Toho University Faculty of Medicine, Tokyo (S.M.); Department of Cardiovascular Medicine, Graduate School of Medicine, The University of Tokyo, Tokyo (S.N., I.K.); Department of Cardiology, Nagoya University Graduate School of Medicine, Nagoya (T.O.); Department of Cardiovascular Medicine, Wakayama Medical University, Wakayama (Y.S.); Global Center for Medical Engineering and Informatics, Osaka University, Suita (T.T.); Department of Cardiovascular Medicine, St. Luke's International Hospital, Tokyo (A.M.), Japan; The Penn Medicine Nudge Unit (A.M), Leonard Davis Institute of Health Economics (A.M), Department of Internal Medicine (A.M.), University of Pennsylvania, Philadelphia, PA, USA; Department of Graduate School of Medicine (Cardiology), International University of Health and Welfare, Okawa (T.K.); Department of Cardiovascular Medicine, Saga University, Saga (K.N.); Division of Cardiovascular Medicine Department of Internal Medicine Kobe University Graduate School of Medicine, Kobe (K.H.), Japan

The first two authors contributed equally to this work (M.I., C.M.).

Refer to Supplementary File for the details of Directors of the Japanese Circulation Society.

Mailing address: Koichi Node, MD, PhD, Department of Cardiovascular Medicine, Saga University, 5-1-1 Nabeshima, Saga 849-8501, Japan. E-mail: node@cc.saga-u.ac.jp

All rights are reserved to the Japanese Circulation Society. For permissions, please e-mail: cj@j-circ.or.jp

ISSN-1346-9843 


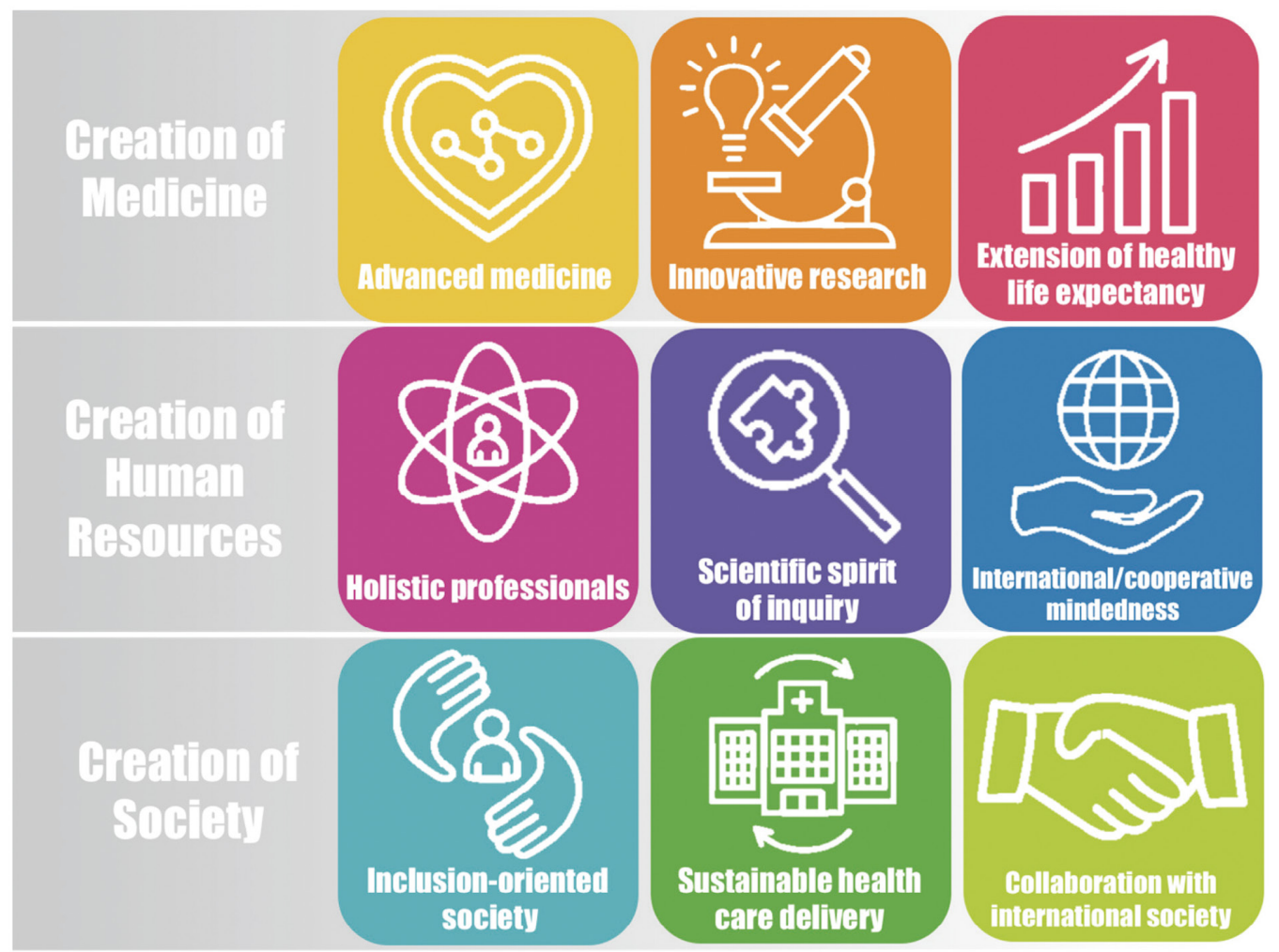

Figure. Strategic goals of the JCS mission. Each of the strategic goals corresponds to a core value.

demonstrating its firm commitment to enhancing cardiovascular health without being distracted or left behind by a rapidly changing world.

Here, the JCS reaffirms the strong conviction of its predecessors and founders by creating a new vision, mission, values, and guiding principles for a new era.

\section{Creating the New Vision, Mission, Values, and Guiding Principles}

The General Affairs Committee appointed 11 young to middle-aged members to the Mission Working Group. These members are expected to be responsible for the future of the JCS and to become leaders in the promotion of cardiovascular health. Additionally, one observer from the standing Directors and two advisers were appointed. The JCS appointed these young members with the aim of uniting the entire JCS to overcoming CVD by providing a fresh perspective of the future and upholding the new mission full of the passion of the younger generation. After a number of online meetings, numerous email discussions, and several rounds of feedback from the Directors of the JCS, the new vision, mission, values, and guiding principles of the JCS were approved by the Board of Councilors in June 2021.

\section{Vision: "To Fight for Cardiovascular Health and Human Welfare"}

As cardiovascular professionals, our enthusiasm to overcome CVD and promote the well-being of all people is unwavering. Due to great developments in cardiovascular medicine and improvements in public health, millions of people have been saved from CVD and this brings happiness and improved quality of life to society. However, because Japan's population is aging and due to changes in the types and prevalence of diseases, the crude death rate due to cardiac disease has not decreased in spite of the decrease in deaths due to stroke in Japan. ${ }^{1}$ We here declare we will make a relentless effort to overcome CVD and contribute to the well-being of people around the world.

\section{Mission: "With a Spirit of Integrity and Fraternity, the Japanese Circulation Society Promotes Holistic Medicine and Advanced Research for the Health and Welfare of Human Beings. We Develop the Human Resources Who Will Inherit This Mission, and in Collaboration With International Communities, Will Pursue the Sustainable Development of Society"}

To achieve this vision, we need to take action on medical care, research, human resources, and society. These details are provided in the next section, entitled "Values". This mission statement and its values explain why the JCS exists and how and what the Society fights for, so that JCS members and leaders can define a coherent set of goals to achieve this vision - the mission leads to the strategic goals (Figure).

Values: "We Create Medicine, Human Resources, and Society for Human Welfare"

Promoting advanced medicine and science, developing the 
human resources who will carry out this mission, and contributing to the welfare of society are the core values.

Creation of Medicine Not only does the JCS promote high clinical standards, it also promotes the practice of advanced medicine for the prevention, diagnosis, and treatment of CVD. The Society will enhance innovative research in basic science, clinical science, and translational research, all of which are essential for the development of cardiovascular medicine. Also, extension of a healthy life expectancy through the development of cardiovascular medicine is crucial. Even though Japan has one of the highest average life expectancies in the world, the difference between the average life expectancy (women: 87.14 years, men: 80.98 years; 2016) and healthy life expectancy (women: 74.79 years, men: 72.14 years; 2016) puts a tremendous burden on society. ${ }^{2}$ The major cause of the need for long-term care in Japan is CVD, including stroke, which accounts for approximately one-fifth of the total reasons for long-term care referral. ${ }^{3}$ Therefore, overcoming CVD and extending the healthy life expectancy is a core value. Furthermore, from the standpoint of patient-centered medicine, improvements in the prognosis of CVD and the quality of life of patients are crucial. It is important that any advanced or innovative medical treatment be based on integrity and compassion for patients, as stated in the Guiding Principle.

Creation of Human Resources The development of people to carry out the Society's mission is another core value. It is essential to nurture health professionals who can provide advanced and holistic medicine, and to develop human resources with a scientific spirit of inquiry who can conduct advanced research in cardiovascular medicine. In addition, having distinguished educators nurturing these professionals is imperative. To achieve these goals, cooperation with many people, not only cardiovascular professionals, but also patients and their families, the local community, scientists and medical practitioners in other fields, administrative bodies, industry, stakeholders, and the public is critical. Furthermore, to fight for cardiovascular health and human welfare worldwide, it is essential to foster medical professionals with an international perspective.

Creation of Society As a professional organization, the JCS has a responsibility to contribute to the creation of a society that enhances cardiovascular health. The JCS has been actively contributing to society, for example by supporting the promotion of the Cerebrovascular and Cardiovascular Disease Control Act, a Japanese national law $^{\mathbf{4}, 5}$ enacted in 2019, and the Japanese National Plan for Promotion of Measures Against Cerebrovascular and Cardiovascular Disease (Japanese National Plan) by the Ministry of Health, Labour and Welfare, Japan, published in 2020.5,6 The JCS also published "The Five-Year Plan for Overcoming Stroke and Cardiovascular Disease" in cooperation with The Japan Stroke Society to enhance the cardiovascular health of society. ${ }^{7}$ We need to promote equality and equity among patients through improvements in healthcare delivery, information services, consultation support, and employment support, and create a society where every person is guaranteed a happy life regardless of whether they or someone close to them has CVD. Although there is no doubt that the ultimate goal is to overcome CVD, aging of the cardiovascular system begins at the time of birth, and we should aim to have a society where all people can live with peace of mind, even if they have CVD. Along with this, we believe that what we are aiming for here is also the spirit of diversity and inclusion.

We need to provide flexible and sustainable healthcare delivery to secure society. The mission of the Sustainable Development Goals (SDGs) set up by the United Nations General Assembly is to achieve a better and more sustainable future for all people and the world. ${ }^{8}$ The JCS recognizes a responsibility to support these goals. We also have to ensure our well-being in order to provide sustainable cardiovascular health care. Not only that, the COVID-19 pandemic has had a substantial effect on medical care worldwide, forcing us to consider the necessity of flexibility and sustainability in healthcare delivery. Lastly, growing society through collaboration with international societies is important. Specifically, the JCS aims to enhance partnerships with Asian countries and promote further globalization. JCS has rejoined the Asian Pacific Society of Cardiology (APSC) and was supposed to host the joint meeting of the $84^{\text {th }}$ Annual Scientific Meeting of the Japanese Circulation Society (JCS2020) and Asian Pacific Society of Cardiology Congress 2020 (APSC2020). Unfortunately, due to the COVID-19 pandemic, the joint meeting with APSC was postponed. However, there are plans to hold a joint meeting with the World Heart Federation (WHC), and the hope is that participating in joint meetings with the APSC and WHC will be a great opportunity to introduce the JCS to others and promote active collaboration with people from all over the world. We hope that the JCS will develop into one of the world's three poles in cooperation with other leading Asian cardiovascular organizations, along with Western medical societies such as the AHA/ACC and ESC.

\section{Guiding Principles: With Integrity, We Accomplish Our Mission to Ensure Equality, Equity, and Transparency. With Humanity, We Create a Healthy Society by Collaborating With People. With Respect for Diversity, We Handle Various Changes in Society With Flexibility}

The 3 guiding principles are those that we must possess as an academic society and as human beings when upholding the Society's vision, mission, and values. The world surrounding us is dramatically and continuously changing and is becoming more and more complex. In this new era, we hope that these guiding principles will assist members in their decisions and actions in contributing to human welfare. As cardiovascular professionals, we must ensure that we act with equality, equity, integrity, and transparency as we carry out our mission. We value humanity, collaboration, and global wellbeing and we respect diversity, inclusion, and flexibility as we evolve with changes in society.

\section{Our Slogan: "For Heart, Health, and Happiness"}

This slogan expresses the hope of the JCS that people's habits will keep their hearts healthy, will eventually lead to the health of their entire bodies, and that being healthy will bring happiness to people around the world. The word "Heart" here refers not only to the organ, but also to the well-being of the mind in a complex society.

It is obvious that we, the JCS, exist to promote cardiovascular health and human welfare. This vision has been present since the establishment of the JCS, and will continue to be upheld by subsequent generations. However, as the new vision, mission, and values are set, we recognize the sensitive changes in society, what is best for a better world, constantly reflect on ourselves, and revise the mission and 
values as needed. We declare that we will continue to make relentless efforts to overcome CVD and work to improve human welfare in cooperation with people all over the world.

\section{Acknowledgments}

We thank all JCS members and associate members, and the secretariat of the JCS for their support in setting up the new vision, mission, values, and guiding principles.

\section{Disclosures}

None.

\section{References}

1. Ministry of Health Labour and Welfare, Japan. Death due to three major causes of death (malignant neoplasm, heart disease, cerebrovascular disease): Overview of age-adjusted mortality rate by prefecture in 2015. [in Japanese]. Published 2017. https://www. mhlw.go.jp/toukei/saikin/hw/jinkou/other/15sibou/dl/04.pdf (accessed September, 2021).

2. World Health Organization. World Health Statistics. WHO, 2020. https://apps.who.int/iris/bitstream/handle/10665/332070/ 9789240005105-eng.pdf (accessed October 2021).

3. Japan Cabinet Office. Annual report on the Ageing Society.
Published 2020. https://www8.cao.go.jp/kourei/english/annualreport/ 2020/pdf/2020.pdf (accessed September, 2021).

4. Ministry of Health Labour and Welfare, Japan. Cerebrovascular and Cardiovascular Disease Control Act [in Japanese]. Published 2018. https://www.mhlw.go.jp/web/t_doc?dataId=80ab6708\&da taType $=0 \&$ pageNo $=1$ (accessed September, 2021).

5. Kuwabara M, Mori M, Komoto S. Japanese National Plan for promotion of measures against cerebrovascular and cardiovascular disease. Circulation 2021; 143: 1929-1931.

6. Ministry of Health Labour and Welfare, Japan. The Japanese National Plan for promotion of measures against cerebrovascular and cardiovascular disease [in Japanese]. Published 2020. https:// www.mhlw.go.jp/content/000688359.pdf (accessed September, 2021).

7. The Japanese Circulation Society and The Japan Stroke Society. The Five-Year Plan for overcoming stroke and cardiovascular disease. [in Japanese]. Published 2021. https://www.j-circ.or.jp/ five_year/files/JCS_five_year_plan_2nd.pdf (accessed September 2021).

8. Nations U. Transforming our world: The 2030 Agenda for Sustainable Development. Published 2015. https://sdgs.un.org/ 2030agenda (accessed September, 2021).

\section{Supplementary Files}

Please find supplementary file(s);

http://dx.doi.org/10.1253/circj.CJ-21-0822 